\section{Vol. 70, No. 6}

The report "Decline in COVID-19 Hospitalization Growth Rates Associated with Statewide Mask Mandates - 10 States, March-October 2020" contained several errors.

On page 212, in the first paragraph, the fifth sentence should have read "After mask mandates had been implemented for $\geq 3$ weeks, hospitalization growth rates declined by $\mathbf{5 . 6}$ percentage points among persons aged $18-39$ years $(95 \% \mathrm{CI}=\mathbf{0 . 9}-10.4)$ and those aged $40-64$ years $(95 \% \mathrm{CI}=\mathbf{1 . 0}-10.2)$."

On page 213 , in the first complete paragraph of the righthand column, the second sentence should have read "The overall COVID-19-associated hospitalization growth rates among all adults declined 2.4 percentage points $(\mathrm{p}$-value $=0.04)$ $<3$ weeks after the implementation week and declined 5.0 percentage points ( $\mathrm{p}$-value $<0.01$ ) during the period $\geq 3$ weeks after the implementation week (Table 2)."

On pages 213-214, the second complete paragraph of the right-hand column should have read "Among persons aged $18-39$ years, the hospitalization growth rates $<3$ weeks after the implementation week were lower than were those during the $<4$ weeks before the implementation week and the implementation week (reference period) when no mask mandate existed, but the estimated percentage point difference $(-2.2)$ was not statistically significant $(\mathrm{p}$-value $=\mathbf{0 . 3 0})($ Figure $)($ Table 2$)$. However, in this population, mask mandates were associated with a statistically significant $\mathbf{5 . 6}$ percentage-point decline in COVID-19 hospitalization growth rates $(\mathrm{p}$-value $\mathbf{=} \mathbf{0 . 0 2})$ $\geq 3$ weeks after the implementation week. Among adults aged 40-64 years, mask mandates were associated with a 2.9 percentage-point reduction in COVID-19 hospitalization growth rates $(\mathrm{p}$-value $=0.03)<3$ weeks after the implementation week. Hospitalization growth rates declined by $\mathbf{5 . 6}$ percentage points ( $\mathrm{p}$-value $=0.02)$ during $\geq 3$ weeks after the implementation week. Among adults aged $\geq 65$ years, COVID-19 hospitalization growth rates declined $<3$ weeks after the implementation week (1.2 percentage points) and $\geq 3$ weeks after the implementation week ( 0.7 percentage points); however, the declines were not statistically significant."

On page 214, there were multiple errors in Table 2. The corrected table is as follows:

TABLE 2. Estimated association between mask mandates and COVID-19-associated hospitalization growth rates in sites with statewide mask mandates, by age group - 10 COVID-19-Associated Hospitalization Surveillance Network sites, ${ }^{*},+$ March-October 2020

\begin{tabular}{|c|c|c|c|c|c|c|c|c|}
\hline \multirow[b]{2}{*}{$\begin{array}{l}\text { Time relative to week mask } \\
\text { mandate was implemented }\end{array}$} & \multicolumn{2}{|l|}{ All ( $\geq 18$ yrs) } & \multicolumn{2}{|l|}{$18-39$ yrs } & \multicolumn{2}{|l|}{$40-64$ yrs } & \multicolumn{2}{|l|}{$\geq 65 \mathrm{yrs}$} \\
\hline & $\begin{array}{l}\text { Percentage point } \\
\text { change }^{*}(95 \% \mathrm{Cl})\end{array}$ & $p$-value & $\begin{array}{l}\text { Percentage point } \\
\text { change }^{*}(95 \% \mathrm{Cl})\end{array}$ & $p$-value & $\begin{array}{l}\text { Percentage point } \\
\text { change }^{*}(95 \% \mathrm{Cl})\end{array}$ & $p$-value & $\begin{array}{l}\text { Percentage point } \\
\text { change }^{*}(95 \% \mathrm{Cl})\end{array}$ & $\mathrm{p}$-value \\
\hline$\geq 4$ weeks before & $-4.3(-10.6$ to 1.9$)$ & 0.17 & $-4.8(-17.0$ to 7.5$)$ & 0.43 & $-4.0(-13.3$ to 5.3$)$ & 0.38 & $-5.3(-15.0$ to 4.4$)$ & 0.27 \\
\hline$<4$ weeks before ${ }^{\S}$ & Referent & - & Referent & - & Referent & - & Referent & - \\
\hline$<3$ weeks after & $-2.4(-4.7$ to -0.1$)$ & 0.04 & $-2.2(-6.4$ to 2.1$)$ & 0.30 & $-2.9(-5.5$ to -0.3$)$ & 0.03 & $-1.2(-3.9$ to 1.5$)$ & 0.38 \\
\hline$\geq 3$ weeks after & $-5.0(-8.6$ to -1.4$)$ & $<0.01$ & $-5.6(-10.4$ to -0.9$)$ & 0.02 & $-5.6(-10.2$ to -1.0$)$ & 0.02 & $-0.7(-5.3$ to 3.9$)$ & 0.76 \\
\hline
\end{tabular}

Abbreviations: $\mathrm{Cl}=$ confidence interval; COVID-19 = coronavirus disease 2019.

* Percentage points are coefficients from the regression models. Reported numbers are from regression models, which controlled for state, age group, time (week), and statewide closing and reopening.

† California, Colorado, Connecticut, Maryland, Michigan, Minnesota, New Mexico, New York, Ohio, and Oregon.

$\S$ This period includes the implementation week (i.e., week zero).

On page 215, the second paragraph of the Summary should have read "During March 22-October 17, 2020, 10 sites participating in the COVID-19-Associated Hospitalization Surveillance Network in states with statewide mask mandates reported a decline in weekly COVID-19-associated hospitalization growth rates by up to $\mathbf{5 . 6}$ percentage points for adults aged 18-64 years after mandate implementation, compared with growth rates during the 4 weeks preceding implementation of the mandate."
The Supplementary Table (https://stacks.cdc.gov/view/ cdc/101127) should have listed the date of statewide reopening for Michigan as June 1, 2020. 